\title{
Mixed Convection Unsteady Stagnation-Point Flow towards a Stretching Sheet with Slip Effects
}

\author{
Hui Chen ${ }^{1,2}$ \\ ${ }^{1}$ School of Mechanical Engineering and Automation, Fuzhou University, Fuzhou, Fujian 350108, China \\ ${ }^{2}$ The State Key Laboratory of Fluid Power Transmission and Control, Zhejiang University, Hangzhou, Zhejiang 310027, China
}

Correspondence should be addressed to Hui Chen; felixceng@fzu.edu.cn

Received 29 January 2014; Accepted 30 March 2014; Published 17 April 2014

Academic Editor: Zhijun Zhang

Copyright $\odot 2014$ Hui Chen. This is an open access article distributed under the Creative Commons Attribution License, which permits unrestricted use, distribution, and reproduction in any medium, provided the original work is properly cited.

\begin{abstract}
The paper studies the unsteady mixed convection flow of an incompressible viscous fluid about a stagnation point on a stretching sheet in presence of velocity and thermal slips. The governing equations are transformed into the ordinary differential equations by using similarity transformations. The transformed equations are solved numerically by an efficient shooting method. The characteristics of the flow and heat transfer features for governing parameters are analyzed and discussed for both the assisting and opposing flows. It is found that dual solutions exist for certain range of buoyancy parameter $\lambda$ which again depend on the unsteadiness parameter $\alpha$ and the slip parameters (i.e., $\delta$ and $\gamma$ ). The numerical results show that the increase of unsteadiness parameter and the slip effects cause increment in the existence range of similarity solution. The effects of unsteadiness parameter, the velocity ratio parameter, and the velocity and thermal slip parameters on the velocity and temperature distributions are analyzed and discussed.
\end{abstract}

\section{Introduction}

The stagnation-point flow due to a stretching sheet has received much attention because of its important practical applications in industry and practical applications, such as extrusion of polymers, glass fiber, the cooling of metallic plate, and the aerodynamics. As a hot topic in fluid mechanics, the two-dimensional stagnation flow was first studied by Hiemenz [1]. The result has been later extended to axisymmetric case by Homann [2] and improved by Howarth [3]. Following these works, various aspects of stagnation-point flow and heat transfer have been studied and many literatures have been generated on this problem [4-11]. The flow becomes time dependent in certain aspects, but the physical situation described in the above studies is under the condition of a steady state. Consequently, it is necessary to consider the unsteadiness of the flow. Nazar et al. [12] considered an unsteady boundary layer flow in the region of the stagnation point on a stretching sheet, while Bhattacharyya $[13,14]$ investigated the unsteady stagnationpoint flow over a shrinking sheet. Sharma and Singh [15] also investigated an unsteady flow near a stagnation point on a stretching sheet in the presence of a time-dependent free stream. Some important properties of unsteady flows on a stretching sheet were described by Bachok et al. [16], Ishak et al. [17], and Hayat et al. [18].

The mixed convection in stagnation flow is a topic of significance in fluid mechanics when the buoyancy forces due to the temperature difference between the surface and the free stream become large, in the sense that both the flow and thermal fields are greatly affected by the buoyancy forces. Much interest has been given to the free and forced convection stagnation-point flows of a viscous fluid. Devi et al. [19] studied the unsteady laminar mixed convection in two-dimensional stagnation-point flows around heated surfaces by taking both cases of an arbitrary wall temperature and arbitrary surface heat flux variations. The unsteady mixed convection flow of a micropolar fluid was studied by Lok et al. [20], where they found the smooth transition from the initial unsteady-state flow to the final steady-state flow. Recently, Ishak et al. [21] reported the existence of dual solutions for both assisting and opposing flows of an 
electrically conducting fluid past a vertical permeable flat plate. Hayat et al. [22] investigated the effects of mixed convection unsteady stagnation-point flow of viscous fluid with variable free stream velocity.

In all the above studies, the assumption of the flow field obeys the conventional no-slip condition at the boundary. However, the assumption of the conventional no-slip condition at the boundary is not true and should be replaced by partial slip boundary condition in certain situations [25]. With a slip at the wall boundary, the flow behavior and the shear stress in the fluid are quite different from those in the no-slip cases. Wang [26] gave an exact solution of the Navier-Stokes equations for the flow due to a stretching boundary with slip. Later, he [27] considered the effect of stagnation slip flow on the heat transfer from a moving plate. Ariel et al. [28, 29] studied the effects of slip on the flow of an elastic-viscous fluid with some other physical features. Many researchers have also investigated the slip flows in different configurations recently [30-35]. It can be pointed out here that less work has been done on the mixed convection flow with slip effect at the boundary. Cao and Baker [36] considered the slip effects on the mixed convective flow and heat transfer from a vertical plate and reported the local nonsimilarity solutions. Mukhopadhyay [37, 38] investigated effects of slip on unsteady mixed convective flow and heat transfer past a stretching surface and a porous stretching surface. Bhattacharyya et al. [39] studied the mixed convective flow adjacent to a vertical permeable stretching sheet in porous medium with slip effects. The similarity solution of the mixed convection boundary layer flow near the stagnation-point on a vertical surface with the slip effect was studied by Aman et al. [40]. Very recently, Nik Long et al. [41] studied mixed convection boundary layer caused by time-dependent velocity and the surface temperature in the two-dimensional unsteady stagnation-point flow over a stretching vertical sheet with the no-slip boundary condition.

Motivated by the above studies, in this paper we investigate the behaviour of the mixed convection unsteady stagnation-point flow towards a stretching sheet with slip effect on the boundary. The momentum and energy equations are solved numerically by a shooting method. The effects of the key parameters on the flow and heat transfer characteristics are analyzed and discussed. To the best of our knowledge, this problem has not been studied before.

\section{Flow Analysis}

Consider an unsteady two-dimensional flow of a viscous and incompressible fluid in the vicinity of a stagnationpoint towards a vertical stretching sheet. The sheet stretching velocity is $u_{w}=a x /(1-c t)$ where $c$ is a parameter showing the unsteadiness of the problem and $a$ is a constant with $a>0$ for a stretching sheet. The free stream velocity is $u_{e}=b x /(1-c t)$, where $b>0$ is the strength of the stagnation flow. The surface temperature $T_{w}$ of the stretching sheet varies with the distance $x$ as $T_{w}=T_{\infty}+T_{0} x /(1-c t)^{2}$, where $T_{\infty}$ is the constant free stream temperature with $T_{0} \geq 0$. The particular forms of the above expressions for $u_{w}, u_{e}$, and
$T_{w}$ have been chosen in order to transform the governing partial differential equations into a set of ordinary differential equations, thereby facilitating the exploration of the effects of the controlling parameters. It should be noticed that the expressions for $u_{w}, u_{e}$, and $T_{w}$ are valid for time $t<1 / c$, and $a, b, c$ have dimension time $\mathrm{e}^{-1}$.

Using the boundary layer approximations, the governing equations for this problem are

$$
\begin{gathered}
\frac{\partial u}{\partial x}+\frac{\partial v}{\partial y}=0 \\
\frac{\partial u}{\partial t}+u \frac{\partial u}{\partial x}+v \frac{\partial u}{\partial y}=\frac{\partial u_{e}}{\partial t}+u_{e} \frac{\partial u_{e}}{\partial x}+v \frac{\partial^{2} u}{\partial y^{2}}+g \beta\left(T-T_{\infty}\right) \\
\frac{\partial T}{\partial t}+u \frac{\partial T}{\partial x}+v \frac{\partial T}{\partial y}=k \frac{\partial^{2} T}{\partial y^{2}}
\end{gathered}
$$

where $u$ and $v$ are the velocities in the $x$ and $y$ directions, $\nu$ is the kinematic viscosity, $g$ is the acceleration due to gravity, $\beta$ is the thermal expansion coefficient, $T$ is the fluid temperature, and $k$ is the thermal diffusivity. The boundary conditions with partial slip are given by

$$
\begin{gathered}
v=0, \quad u=u_{w}+L v \frac{\partial u}{\partial y}, \quad T=T_{w}+M \frac{\partial T}{\partial y} \quad \text { at } y=0, \\
u=u_{e}, \quad T=T_{\infty} \quad \text { as } y \longrightarrow \infty .
\end{gathered}
$$

Here $L=l \sqrt{1-c t}$ and $M=m \sqrt{1-c t}$ are the velocity slip factor and the thermal slip factor and $l$ and $m$ are the initial values of velocity and thermal slip factors, respectively.

To obtain the similarity solution, we now introduce the following similarity transformations:

$$
\begin{gathered}
\eta=y \sqrt{\frac{b}{v(1-c t)}}, \quad \psi=x f(\eta) \sqrt{\frac{b v}{1-c t}}, \\
\theta=\frac{T-T_{\infty}}{T_{w}-T_{\infty}}
\end{gathered}
$$

where $\psi$ is the steam function which automatically assures mass conservation (1). The velocity components are obtained as

$$
\begin{gathered}
u=\frac{\partial \psi}{\partial y}=\frac{b x}{1-c t} f^{\prime}(\eta), \\
v=-\frac{\partial \psi}{\partial x}=-f(\eta) \sqrt{\frac{b v}{1-c t}} .
\end{gathered}
$$

Substituting (5) into (2) and (3), we get

$$
\begin{gathered}
f^{\prime \prime \prime}+f f^{\prime \prime}-f^{\prime 2}+\alpha\left(1-f^{\prime}-\frac{\eta f^{\prime \prime}}{2}\right)+\lambda \theta+1=0, \\
\theta^{\prime \prime}+\operatorname{Pr}\left(f \theta^{\prime}-f^{\prime} \theta\right)-\frac{\operatorname{Pr} \alpha}{2}\left(\eta \theta^{\prime}+4 \theta\right)=0,
\end{gathered}
$$


TABle 1: Values of $f^{\prime \prime}(0)$ and $-\theta^{\prime}(0)$ for different values of Pr when $\delta=\gamma=0, \alpha=0, \varepsilon=1$, and $\lambda=1$ for assisting flow.

\begin{tabular}{lcccccc}
\hline \multirow{2}{*}{ Pr } & \multicolumn{2}{c}{ Ishak et al. [23] } & \multicolumn{2}{c}{ Pal [24] } & \multicolumn{2}{c}{ Present work } \\
& $f^{\prime \prime}(0)$ & $-\theta^{\prime}(0)$ & $f^{\prime \prime}(0)$ & $-\theta^{\prime}(0)$ & $f^{\prime \prime}(0)$ & $-\theta^{\prime}(0)$ \\
\hline 0.72 & 0.3645 & 1.0931 & 0.36449 & 1.09331 & 0.36449 & 1.09311 \\
6.8 & 0.1804 & 3.2902 & 0.18042 & 3.28957 & 0.18042 & 3.28957 \\
20.0 & 0.1175 & 5.6230 & 0.11750 & 5.62014 & 0.11750 & 5.62013 \\
40.0 & 0.0873 & 7.9463 & 0.08724 & 7.93831 & 0.08724 & 7.93830 \\
60.0 & 0.0729 & 9.7327 & 0.07284 & 9.71801 & 0.07284 & 9.71800 \\
80.0 & 0.0640 & 11.2413 & 0.06394 & 11.21875 & 0.06394 & 11.21873 \\
100.0 & 0.0578 & 12.5726 & 0.05773 & 12.54113 & 0.05773 & 12.54109 \\
\hline
\end{tabular}

where $\alpha=c / b$ is the unsteadiness parameter, $\operatorname{Pr}=\nu / k$ is the Prandtl number, $\lambda$ is the buoyancy or mixed convection parameter defined as $\lambda=\mathrm{Gr}_{x} / \mathrm{Re}_{x}^{2}$ with $\mathrm{Gr}_{x}=g \beta\left(T_{w}-\right.$ $\left.T_{\infty}\right) x^{3} / \nu^{2}$ being the local Grashof number, and $\operatorname{Re}_{x}=u_{e} x / v$ is the local Reynolds number. It should be noticed that $\lambda=$ $g \beta T_{0} / b^{2}$ is a constant with $\lambda>0$ and $\lambda<0$ corresponding to assisting flow and opposing flow, respectively. The corresponding boundary conditions (4) become

$$
\begin{gathered}
f(0)=0, \\
f^{\prime}(0)=\varepsilon+\delta f^{\prime \prime}(0), \\
\theta(0)=1+\gamma \theta^{\prime}(0), \\
f^{\prime}(\infty)=1, \quad \theta(\infty)=0,
\end{gathered}
$$

where $\delta=l \sqrt{b v}$ and $\gamma=m \sqrt{b / v}$ are the dimensionless velocity and thermal slip parameters, respectively, and $\varepsilon=$ $a / b$ is the ratio of stretching parameter and free steam velocity parameter.

The physical quantities of interest are the skin friction coefficient $C_{f}$ and the local Nusselt number $\mathrm{Nu}_{x}$, which are defined as

$$
C_{f}=\frac{\tau_{w}}{\rho u_{e}^{2} / 2}, \quad \mathrm{Nu}_{x}=\frac{x q_{w}}{\kappa\left(T_{w}-T_{\infty}\right)},
$$

where the surface shear stress $\tau_{w}$ and the surface heat flux $q_{w}$ are given by

$$
\tau_{w}=\mu\left(\frac{\partial u}{\partial y}\right)_{y=0}, \quad q_{w}=-\kappa\left(\frac{\partial T}{\partial y}\right)_{y=0} .
$$

Using the similarity transformations (5) and the relation (13) into (12), we get

$$
\frac{1}{2} C_{f} \sqrt{\mathrm{Re}_{x}}=f^{\prime \prime}(0), \quad \frac{\mathrm{Nu}_{x}}{\sqrt{\mathrm{Re}_{x}}}=-\theta^{\prime}(0),
$$

with $\operatorname{Re}_{x}=u_{e} x / v$ being the local Reynolds number.

\section{Results and Discussion}

The nonlinear ordinary differential (7) subject to the boundary conditions (8)-(11) have been numerically solved using
TABle 2: Values of $f^{\prime \prime}(0)$ and $-\theta^{\prime}(0)$ for different values of Pr when $\delta=\gamma=0, \alpha=0, \varepsilon=1$, and $\lambda=-1$ for opposing flow.

\begin{tabular}{lcccccc}
\hline \multirow{3}{*}{ Pr } & \multicolumn{2}{c}{ Ishak et al. [23] } & \multicolumn{2}{c}{ Pal [24] } & \multicolumn{2}{c}{ Present work } \\
& $f^{\prime \prime}(0)$ & $-\theta^{\prime}(0)$ & $f^{\prime \prime}(0)$ & $-\theta^{\prime}(0)$ & $f^{\prime \prime}(0)$ & $-\theta^{\prime}(0)$ \\
\hline 0.72 & -0.3852 & 1.0293 & -0.38519 & 1.02925 & -0.38519 & 1.02925 \\
6.8 & -0.1832 & 3.2466 & -0.18323 & 3.24609 & -0.18323 & 3.24608 \\
20.0 & -0.1183 & 5.5923 & -0.11831 & 5.58960 & -0.11831 & 5.58959 \\
40.0 & -0.0876 & 7.9227 & -0.08758 & 7.91491 & -0.08758 & 7.91489 \\
60.0 & -0.0731 & 9.7126 & -0.07304 & 9.69818 & -0.07304 & 9.69817 \\
80.0 & -0.0642 & 11.2235 & -0.06408 & 11.20118 & -0.06408 & 11.20117 \\
100.0 & -0.0579 & 12.5564 & 0.05783 & 12.52519 & -0.05783 & 12.52514 \\
\hline
\end{tabular}

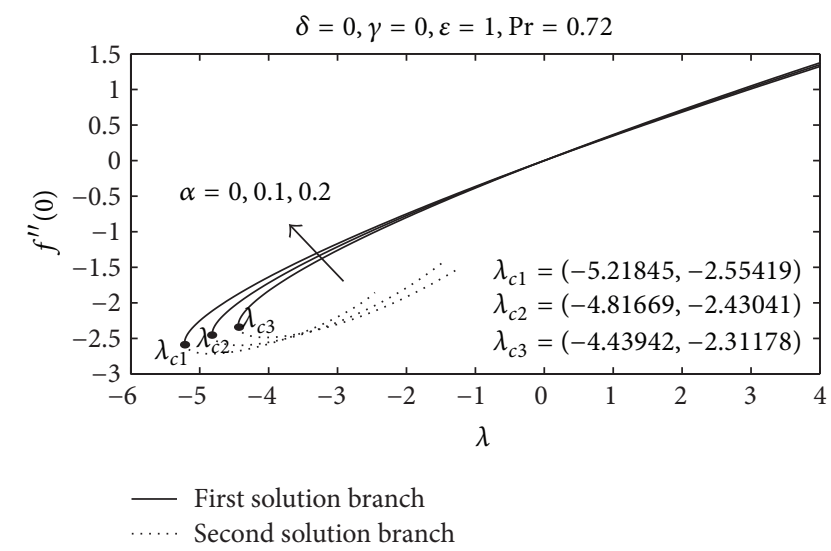

FIGURE 1: Variation of $f^{\prime \prime}(0)$ with $\lambda$ for different values of $\alpha$ under no-slip boundary condition.

an improved shooting method described by Zheng et al. [42]. The results show the influences of some important nondimensional parameters on the feature of the flow and the heat transfer characteristics. In order to validate the numerical method used in this study and to judge the accuracy of the present analysis, the present values of the skin friction coefficient $f^{\prime \prime}(0)$ and the local Nusselt number $-\theta^{\prime}(0)$ for different values of Pr are compared with those obtained by Ishak et al. [23] and Pal [24] when $\delta=0$ and $\gamma=0$ (absence of the slip effect), $\alpha=0$ (the steady-state flow), $\varepsilon=1$, and $\lambda= \pm 1$ for assisting and opposing flow. The quantitative comparisons are shown in Tables 1 and 2 and found to be in very good agreement.

The skin friction coefficient, local Nusselt number, velocity, and temperature profiles are shown in Figures 1, 2, 3, 4, $5,6,7,8,9,10,11$, and 12 . Figures 1 and 2 show the variation of skin friction coefficient $f^{\prime \prime}(0)$ and local Nusselt number $-\theta^{\prime}(0)$ with $\lambda$ for the unsteadiness parameter $\alpha=0,0.1,0.3$ in the absence of slip when the velocity ratio parameter $\varepsilon=1$ and the Prandtl number $\operatorname{Pr}=0.72$. Moreover, the variations of $f^{\prime \prime}(0)$ and $-\theta^{\prime}(0)$ in the presence of slip (i.e., $\delta=0.2, \gamma=1$ ) are, respectively, shown in Figures 3 and 4.

It is seen from Figures $1-4$ that the dual solutions exist for the buoyancy opposing flow $(\lambda<0)$, whereas the solution is unique for the assisting flow $(\lambda>0)$. It is worth mentioning that $-\theta^{\prime}(0)>0$ for all values of the parameters as shown 


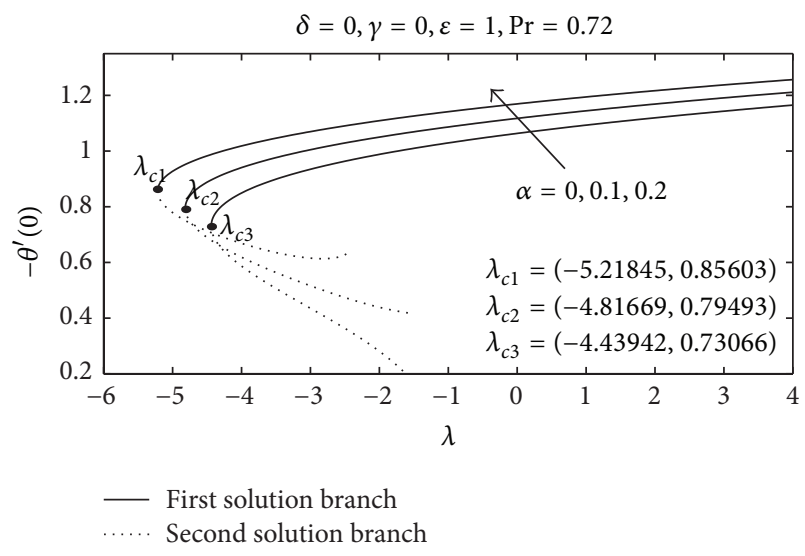

Figure 2: Variation of $-\theta^{\prime}(0)$ with $\lambda$ for different values of $\alpha$ under no-slip boundary condition.

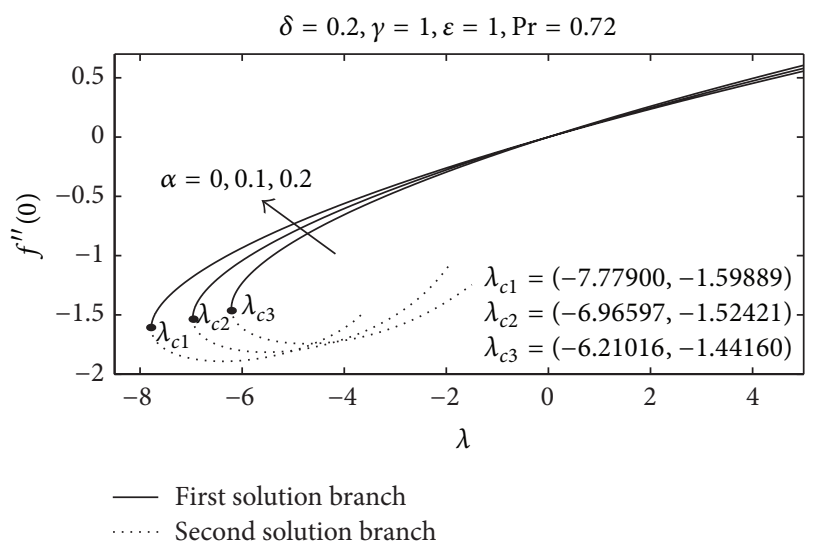

Figure 3: Variation of $f^{\prime \prime}(0)$ for different values of $\alpha$ under slip boundary condition.

in Figures 3 and 4, which means that the heat is transferred from the hot surface to the cool fluid. In the dual solutions range, we identify the first solution and second solution in the following discussion by the principle that the first solution has the higher values of $f^{\prime \prime}(0)$ and $-\theta^{\prime}(0)$ for a given $\lambda$ than the second solution. It is observed that no solutions exist when $\lambda<\lambda_{c}<0$, where $\lambda_{c}$ is the critical value for which (7) have no solutions. Further, these figures show that the solutions could be obtained for all values of $\lambda>0$ (assisting flow), while for $\lambda<0$ (opposing flow), solutions exist only when $\lambda_{c}<\lambda<0$. Based on our computations, we find that $\lambda_{c}=-4.43942,-4.81669,-5.21845$, respectively, for $\alpha=$ $0,0.1,0.2$ under nonslip condition shown in Figures 1 and 2, and $\lambda_{c}=-6.21016,-6.96597,-7.77900$, respectively, for $\alpha=$ $0,0.1,0.2$ under slip condition shown in Figures 3 and 4 . Thus, it can be concluded that the solution domain expands as the unsteadiness parameter $\alpha$ increases. Moreover, the velocity and thermal slip cause more increment in the existence range of similarity solution. It is also noteworthy that the impact of $\alpha$ on $-\theta^{\prime}(0)$ in Figures 2 and 4 is more pronounced than on the $f^{\prime \prime}(0)$ in Figures 1 and 3.

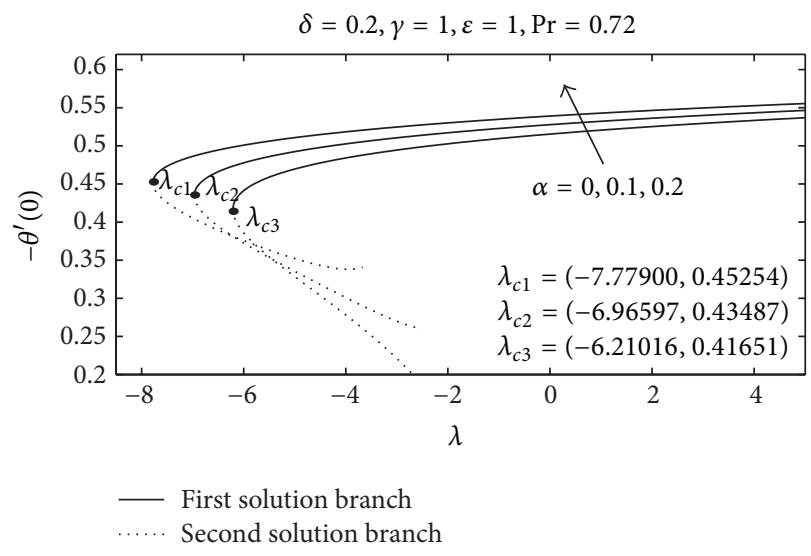

FIGURE 4: Variation of $-\theta^{\prime}(0)$ with $\lambda$ for different values of $\alpha$ under slip boundary condition.

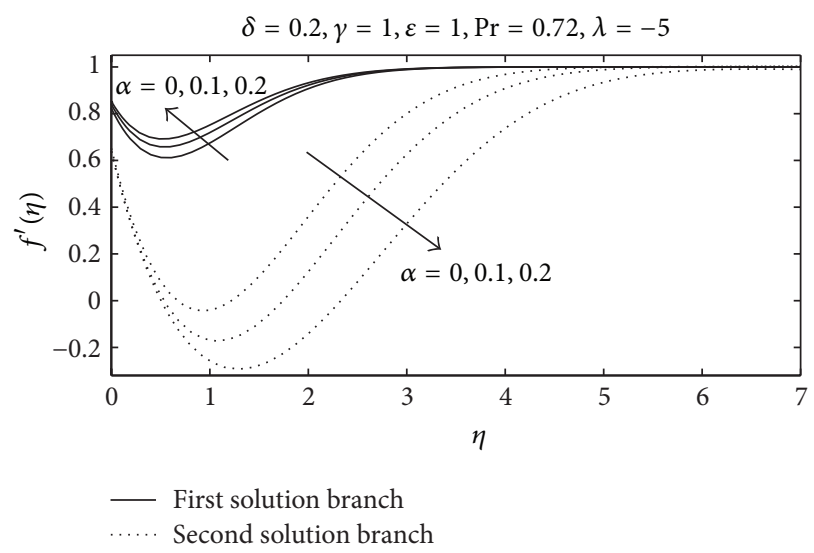

FIGURE 5: Influence of unsteady parameter $\alpha$ on velocity profiles $f^{\prime}(\eta)$.

In Figures 5-8, velocity profiles $f^{\prime}(\eta)$ and temperature profiles $\theta(\eta)$ are shown for different values of the unsteadiness parameter $\alpha$ and velocity ratio parameter $\varepsilon$, respectively, in presence of $\operatorname{slip}(\delta=0.2, \gamma=1)$ for both the first and second solution branches. It is seen from Figures 5 and 7 that, for the first solution branch, the velocity $f^{\prime}(\eta)$ increases with unsteadiness parameter $\alpha$ or the velocity ratio parameter $\varepsilon$ and this implies an accompanying reduction of the thickness of the momentum boundary layer. The opposite trend can be observed for the second solution branch. From Figures 6 and 8 , it is observed that the temperature $\theta(\eta)$ decreases with the increase of $\alpha$ or $\varepsilon$ for the first solution branch while a different trend is observed for the second solution branch.

The samples of the $f^{\prime}(\eta)$ and $\theta(\eta)$ for the selected values of the slip parameters are investigated in Figures 9-12. The effect of velocity slip parameter $\delta$ is shown in Figures 9 and 10, while the influence of thermal slip parameter $\gamma$ is shown in Figures 11 and 12. It is clear that effects of the two type slips on velocity and temperature profiles are opposite. For the first solution branch, an increase in velocity slip parameter $\delta$ would decrease $f^{\prime}(\eta)$ and increase $\theta(\eta)$, while an increase in thermal slip parameter $\gamma$ would increase $f^{\prime}(\eta)$ and decrease $\theta(\eta)$. For the second solution branch, the velocity 


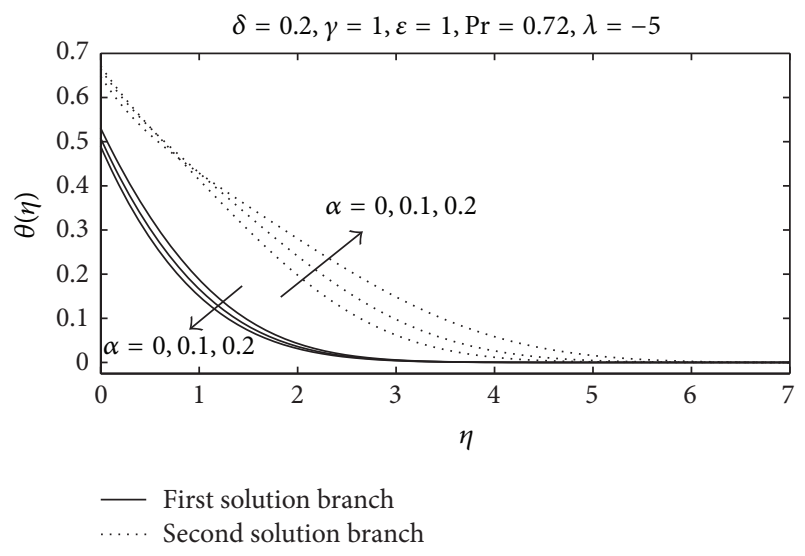

FIGURE 6: Influence of unsteady parameter $\alpha$ on temperature profiles $\theta(\eta)$

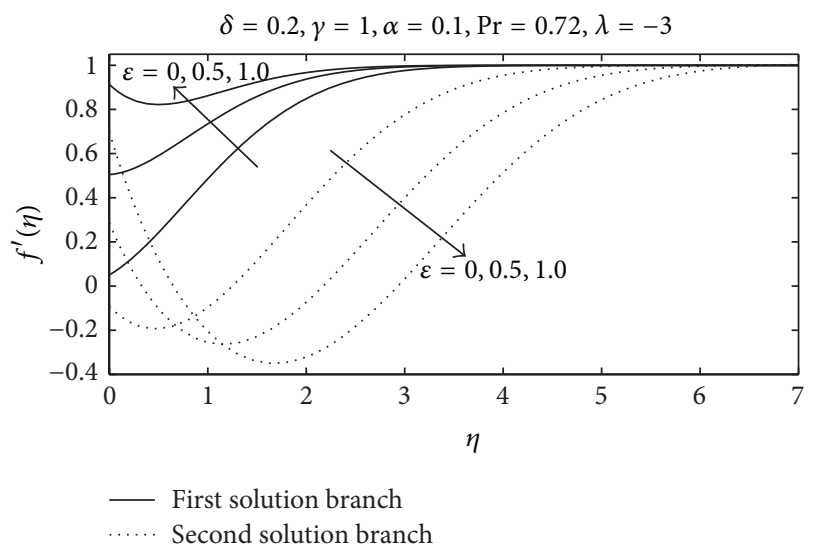

FIGURE 7: Influence of velocity ratio parameter $\varepsilon$ on velocity profiles $f^{\prime}(\eta)$.

and temperature profiles $\left(f^{\prime}(\eta)\right.$ and $\left.\theta(\eta)\right)$ show the opposite trend.

It is evident from Figures 5-12 that the first solution displays the thinner boundary layer thickness compared with the second solution. From Figures 5, 7, 9, and 10, it is interesting to note that for the second solution branch the value of $f^{\prime}(\eta)$ initially decreases with $\eta$ to a negative value and for small $\eta$ it starts to increase and ultimately it becomes the positive value 1 . Thus the velocity profiles exhibit reverse flow $\left(f^{\prime}(\eta)<0\right)$ near the wall $(\eta=0)$. Moreover, the samples of velocity and temperature profiles presented in Figures 5-12 show that the boundary conditions (11) are asymptotically satisfied, which supports the validity of the obtained numerical results.

\section{Conclusions}

In this paper, we have studied the mixed convection unsteady boundary layer flow and heat transfer about a stagnationpoint towards a stretching sheet in the presence of both velocity and thermal slip conditions at the boundary. The

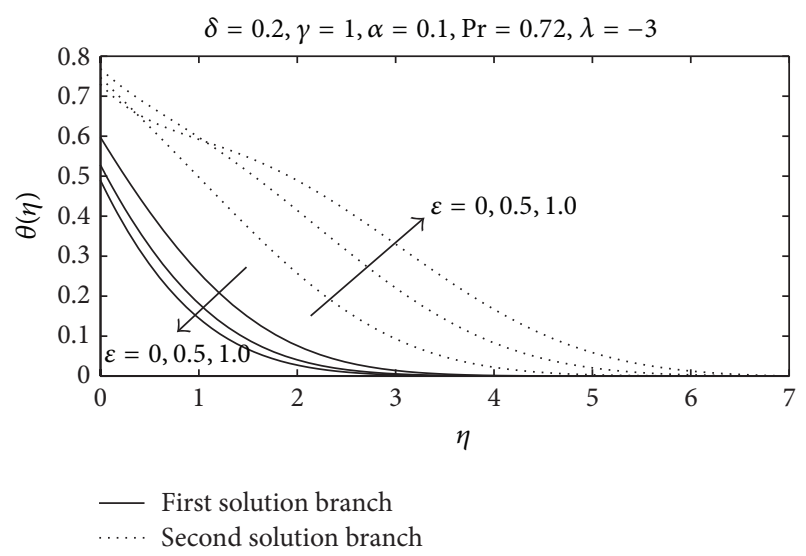

FIGURE 8: Influence of velocity ratio parameter $\varepsilon$ on temperature profiles $\theta(\eta)$.

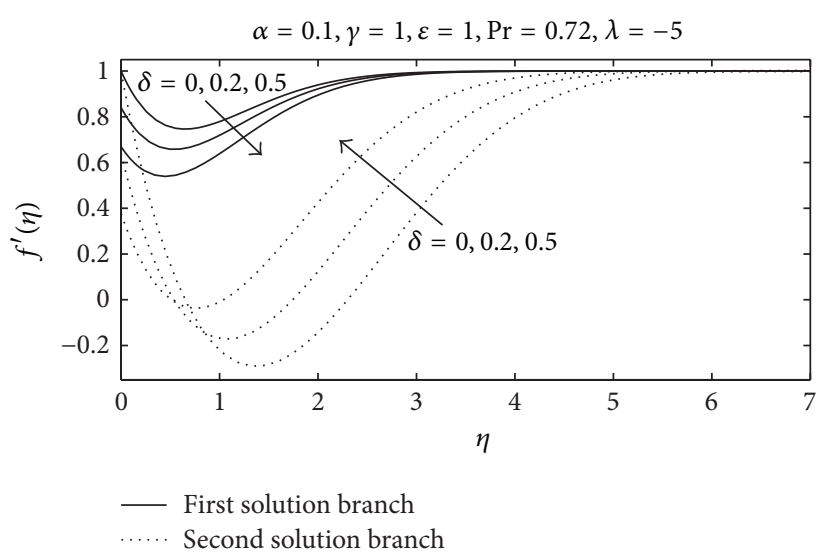

FIGURE 9: Influence of velocity slip parameters $\delta$ on velocity profiles $f^{\prime}(\eta)$.

governing equations are reduced to the ordinary differential equations by the similarity transformation and then numerically solved to obtain the influence of key parameters on the skin friction coefficient, the local Nusselt number, the velocity, and temperature profiles. The existence and duality of solutions are displayed in Figures 1-4 with the buoyancy parameter $\lambda$, and the range of $\lambda$ for which the similarity solution exists increases with the unsteadiness parameter $\alpha$. Moreover, the velocity and thermal slip parameters cause more increment in the existence range of similarity solution. The effects of the unsteadiness parameter $\alpha$, velocity ratio parameter $\varepsilon$, velocity slip parameter $\delta$, and thermal slip parameter $\gamma$ on the velocity and temperature profiles are shown in Figures 5-12. It is noticed that the reverse flow occurs near the sheet. Different flow behavior is observed with the first and second solution branches.

\section{Conflict of Interests}

The author declares that there is no conflict of interests regarding the publication of this paper. 


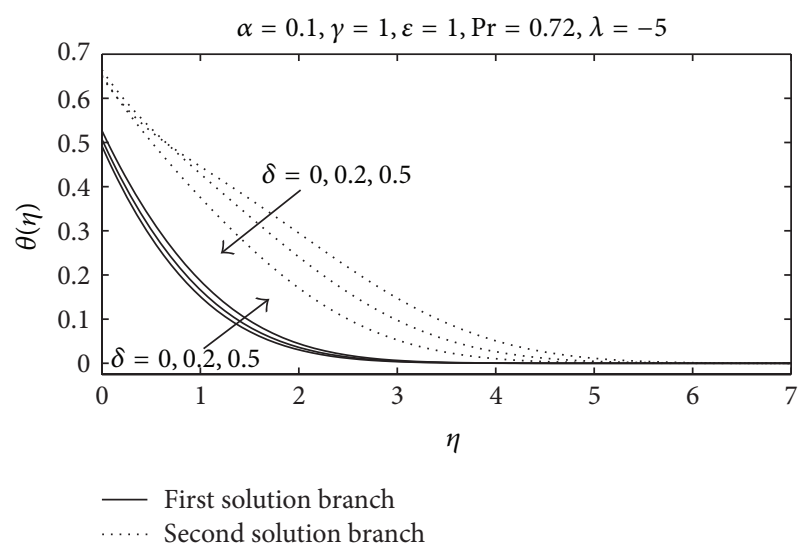

FIGURE 10: Influence of velocity slip parameters $\delta$ on temperature profiles $\theta(\eta)$.

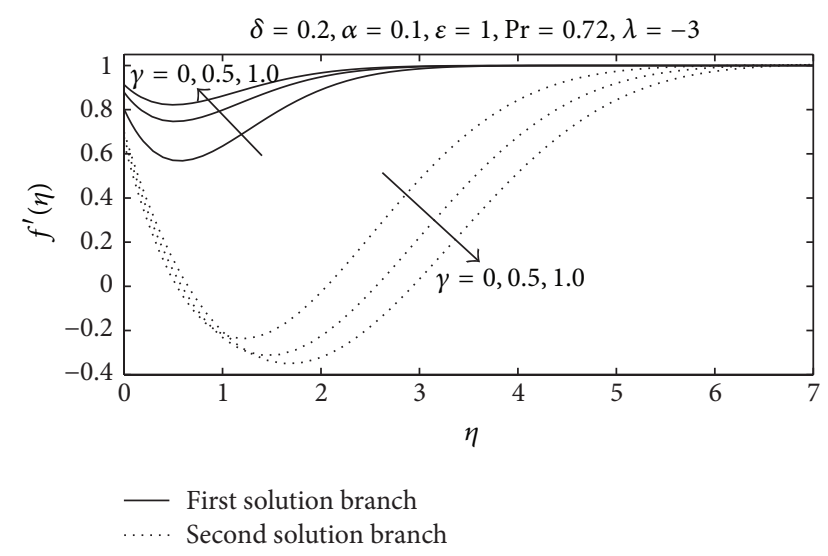

FIGURE 11: Influence of thermal slip parameters $\gamma$ on velocity profiles $f^{\prime}(\eta)$.

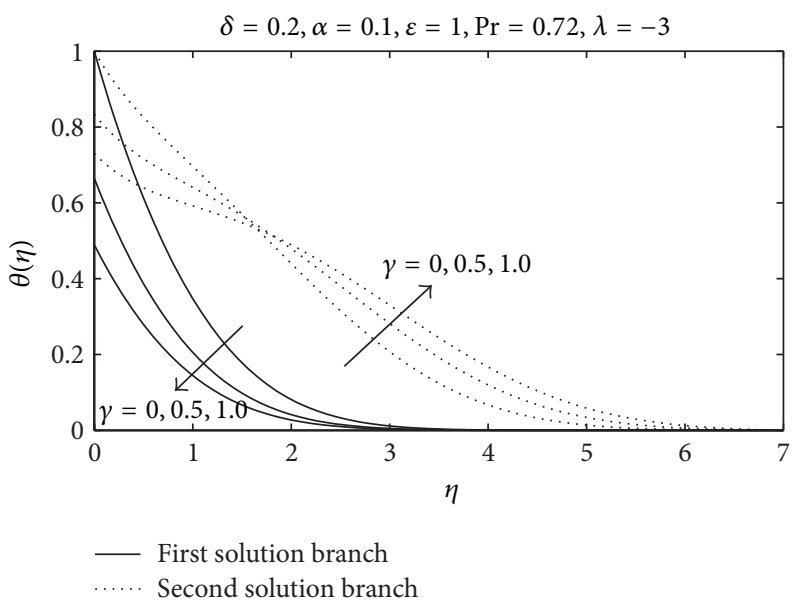

FIGURE 12: Influence of thermal slip parameters $\gamma$ on temperature profiles $\theta(\eta)$.

\section{Acknowledgments}

This work is supported by the National Natural Science Foundation of China (Grant no. 51305080), Fujian Provincial Natural Science Foundation of China (Grant no. 2012J05089), and Visiting Scholar Foundation of Key Lab in University (Grant no. GZKF-201217).

\section{References}

[1] K. Hiemenz, "Die Grenzschicht in Einem in Dem Gleichformingen Flussigkeitsstrom Eingetauchten Gerade Kreiszlinder," Dingler's Polytechnic Journal, vol. 326, pp. 321-410, 1911.

[2] F. Homann, "Die Einfluss grosse Zähigkeit bei der Strömung um der Zylinder und um die Kugel," Zeitschrift für Angewandte Mathematik und Mechanik, vol. 16, no. 3, pp. 153-164, 1936.

[3] L. Howarth, "On the solution of the laminar boundary layer equations," Proceedings of the Royal Society of London, vol. 164, no. 919, pp. 547-579, 1938.

[4] T. C. Chiam, "Stagnation-point flow towards a stretching plate," Journal of the Physical Society of Japan, vol. 63, no. 6, pp. 24432444, 1994.

[5] T. R. Mahapatra and A. S. Gupta, "Heat transfer in stagnationpoint flow towards a stretching sheet," Heat and Mass Transfer, vol. 38, no. 6, pp. 517-521, 2002.

[6] G. C. Layek, S. Mukhopadhyay, and S. A. Samad, "Heat and mass transfer analysis for boundary layer stagnationpoint flow towards a heated porous stretching sheet with heat absorption/generation and suction/blowing," International Communications in Heat and Mass Transfer, vol. 34, no. 3, pp. 347-356, 2007.

[7] A. Ishak, R. Nazar, and I. Pop, "Mixed convection stagnation point flow of a micropolar fluid towards a stretching sheet," Meccanica, vol. 43, no. 4, pp. 411-418, 2008.

[8] K. Bhattacharyya, S. Mukhopadhyay, and G. C. Layek, "Reactive solute transfer in magnetohydrodynamic boundary layer stagnation-point flow over a stretching sheet with suction/blowing," Chemical Engineering Communications, vol. 199, no. 3, pp. 368-383, 2012.

[9] K. Bhattacharyya, Md. G. Arif, and W. Ali Pramanik, "MHD boundary layer stagnation-point flow and mass transfer over a permeable shrinking sheet with suction/blowing and chemical reaction," Acta Technica, vol. 57, no. 1, pp. 1-15, 2012.

[10] K. Bhattacharyya and K. Vajravelu, "Stagnation-point flow and heat transfer over an exponentially shrinking sheet," Communications in Nonlinear Science and Numerical Simulation, vol. 17, no. 7, pp. 2728-2734, 2012.

[11] K. Bhattacharyya, "Heat transfer in boundary layer stagnationpoint flow towards a shrinking sheet with non-uniform heat flux," Chinese Physics B, vol. 22, no. 7, Article ID 074705, 6 pages, 2013.

[12] R. Nazar, N. Amin, D. Filip, and I. Pop, "Unsteady boundary layer flow in the region of the stagnation point on a stretching sheet," International Journal of Engineering Science, vol. 42, no. 11-12, pp. 1241-1253, 2004.

[13] K. Bhattacharyya, "Dual solutions in unsteady stagnation-point flow over a shrinking sheet," Chinese Physics Letters, vol. 28, no. 8, Article ID 084702, 2011.

[14] K. Bhattacharyya, "Heat transfer in unsteady boundary layer stagnation-point flow towards a shrinking sheet," Ain Shams Engineering Journal, vol. 44, no. 2, pp. 259-264, 2013. 
[15] P. R. Sharma and G. Singh, "Unsteady flow about a stagnation point on a stretching sheet in the presence of variable freestream," Thammasat International Journal of Science and Technology, vol. 13, no. 1, pp. 11-16, 2008.

[16] N. Bachok, A. Ishak, and R. Nazar, "Flow and heat transfer over an unsteady stretching sheet in a micropolar fluid," Meccanica, vol. 46, no. 5, pp. 935-942, 2011.

[17] A. Ishak, R. Nazar, and I. Pop, "Heat transfer over an unsteady stretching permeable surface with prescribed wall temperature," Nonlinear Analysis: Real World Applications, vol. 10, no. 5, pp. 2909-2913, 2009.

[18] T. Hayat, M. Qasim, and Z. Abbas, "Homotopy solution for the unsteady three-dimensional MHD flow and mass transfer in a porous space," Communications in Nonlinear Science and Numerical Simulation, vol. 15, no. 9, pp. 2375-2387, 2010.

[19] C. D. S. Devi, H. S. Takhar, and G. Nath, "Unsteady mixed convection flow in stagnation region adjacent to a vertical surface," Wärme- und Stoffübertragung, vol. 26, no. 2, pp. 71-79, 1991.

[20] Y. Y. Lok, N. Amin, and I. Pop, "Unsteady mixed convection flow of a micropolar fluid near the stagnation point on a vertical surface," International Journal of Thermal Sciences, vol. 45, no. 12, pp. 1149-1157, 2006.

[21] A. Ishak, R. Nazar, N. Bachok, and I. Pop, "MHD mixed convection flow near the stagnation-point on a vertical permeable surface," Physica A: Statistical Mechanics and its Applications, vol. 389, no. 1, pp. 40-46, 2010.

[22] T. Hayat, S. A. Shehzad, A. Rafique, and M. Y. Malik, "Mixed convection unsteady stagnation point flow over a stretching sheet with heat transfer in the presence of variable free stream," International Journal for Numerical Methods in Fluids, vol. 68, no. 4, pp. 483-493, 2012.

[23] A. Ishak, R. Nazar, and I. Pop, "Mixed convection boundary layers in the stagnation-point flow toward a stretching vertical sheet," Meccanica, vol. 41, no. 5, pp. 509-518, 2006.

[24] D. Pal, "Heat and mass transfer in stagnation-point flow towards a stretching surface in the presence of buoyancy force and thermal radiation," Meccanica, vol. 44, no. 2, pp. 145-158, 2009.

[25] H. I. Andersson, "Slip flow past a stretching surface," Acta Mechanica, vol. 158, no. 1-2, pp. 121-125, 2002.

[26] C. Y. Wang, "Flow due to a stretching boundary with partial slip-an exact solution of the Navier-Stokes equations," Chemical Engineering Science, vol. 57, no. 17, pp. 3745-3747, 2002.

[27] C. Y. Wang, "Stagnation slip flow and heat transfer on a moving plate," Chemical Engineering Science, vol. 61, no. 23, pp. 76687672, 2006.

[28] P. D. Ariel, T. Hayat, and S. Asghar, "The flow of an elasticoviscous fluid past a stretching sheet with partial slip," Acta Mechanica, vol. 187, no. 1-4, pp. 29-35, 2006.

[29] P. D. Ariel, "Two dimensional stagnation point flow of an elastico-viscous fluid with partial slip," Zeitschrift für Angewandte Mathematik und Mechanik, vol. 88, no. 4, pp. 320-324, 2008.

[30] P. D. Ariel, "Axisymmetric flow due to a stretching sheet with partial slip," Computers \& Mathematics with Applications, vol. 54, no. 7-8, pp. 1169-1183, 2007.

[31] T. Fang, J. Zhang, and S. Yao, "Slip MHD viscous flow over a stretching sheet-an exact solution," Communications in Nonlinear Science and Numerical Simulation, vol. 14, no. 11, pp. 3731-3737, 2009.
[32] K. Bhattacharyya, S. Mukhopadhyay, and G. C. Layek, "Slip effects on an unsteady boundary layer stagnation-point flow and heat transfer towards a stretching sheet," Chinese Physics Letters, vol. 28, no. 9, Article ID 094702, 5 pages, 2011.

[33] S. Mukhopadhyay and R. S. R. Gorla, "Effects of partial slip on boundary layer flow past a permeable exponential stretching sheet in presence of thermal radiation," Heat and Mass Transfer, vol. 48, no. 10, pp. 1773-1781, 2012.

[34] S. Mukhopadhyay, P. R. De, K. Bhattacharyya, and G. C. Layek, "Slip effects on mixed convection flow along a stretching cylinder," International Journal of Heat and Technology, vol. 30, no. 2, pp. 19-24, 2012.

[35] K. Bhattacharyya, K. Vajravelu, and T. Hayat, "Slip effects on the parametric space and the solution for boundary layer flow of casson fluid over a porous stretching/shrinking sheet," International Journal of Fluid Mechanics Research, vol. 40, no. 6, pp. 482-493, 2013.

[36] K. Cao and J. Baker, "Slip effects on mixed convective flow and heat transfer from a vertical plate," International Journal of Heat and Mass Transfer, vol. 52, no. 15-16, pp. 3829-3841, 2009.

[37] S. Mukhopadhyay, "Effects of slip on unsteady mixed convective flow and heat transfer past a stretching surface," Chinese Physics Letters, vol. 27, no. 12, Article ID 124401, 4 pages, 2010.

[38] S. Mukhopadhyay, "Effects of slip on unsteady mixed convective flow and heat transfer past a porous stretching surface," Nuclear Engineering and Design, vol. 241, no. 8, pp. 2660-2665, 2011.

[39] K. Bhattacharyya, M. S. Uddin, and G. C. Layek, "Effect of partial slip on boundary layer mixed convective flow adjacent to a vertical permeable stretching sheet in porous medium," Acta Technica, vol. 58, no. 1, pp. 27-39, 2013.

[40] F. Aman, A. Ishak, and I. Pop, "Mixed convection boundary layer flow near stagnation-point on vertical surface with slip," Applied Mathematics and Mechanics, vol. 32, no. 12, pp. 15991606, 2011.

[41] N. M. A. Nik Long, L. F. Koo, T. J. Wong, and M. Suali, "Mixed convection boundary layers with prescribed temperature in the unsteady stagnation point flow toward a stretching vertical sheet," Mathematical Problems in Engineering, vol. 2013, Article ID 195360, 10 pages, 2013.

[42] L. C. Zheng, C. Liang, and X. X. Zhang, "A numerical method for solving the boundary layer equations of laminar natural convention about a vertical plate," Journal of University of Science and Technology Beijing, vol. 14, no. 1, pp. 33-35, 2007. 


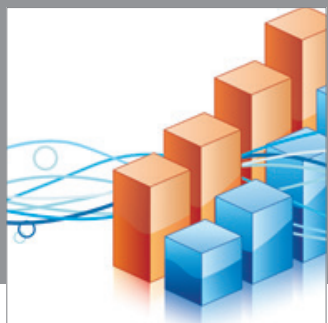

Advances in

Operations Research

mansans

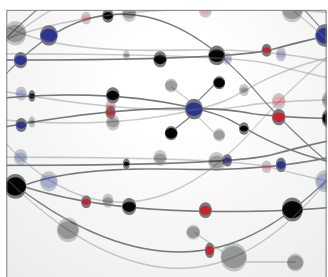

The Scientific World Journal
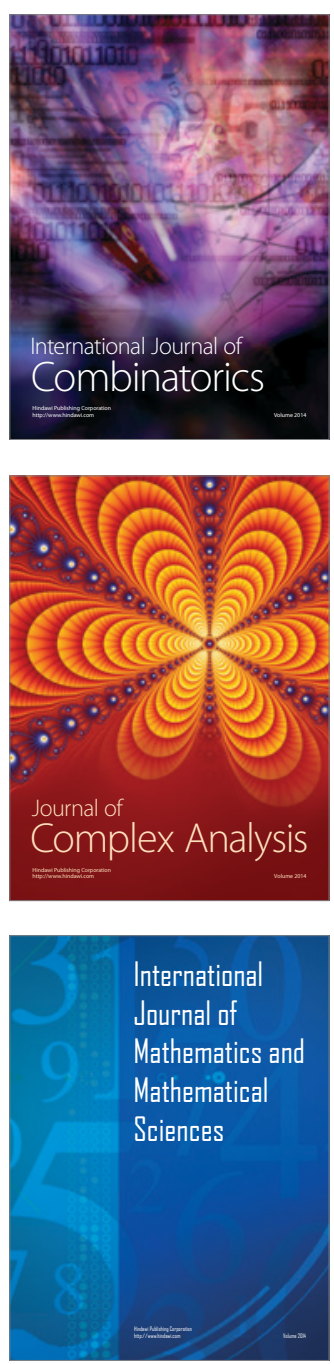
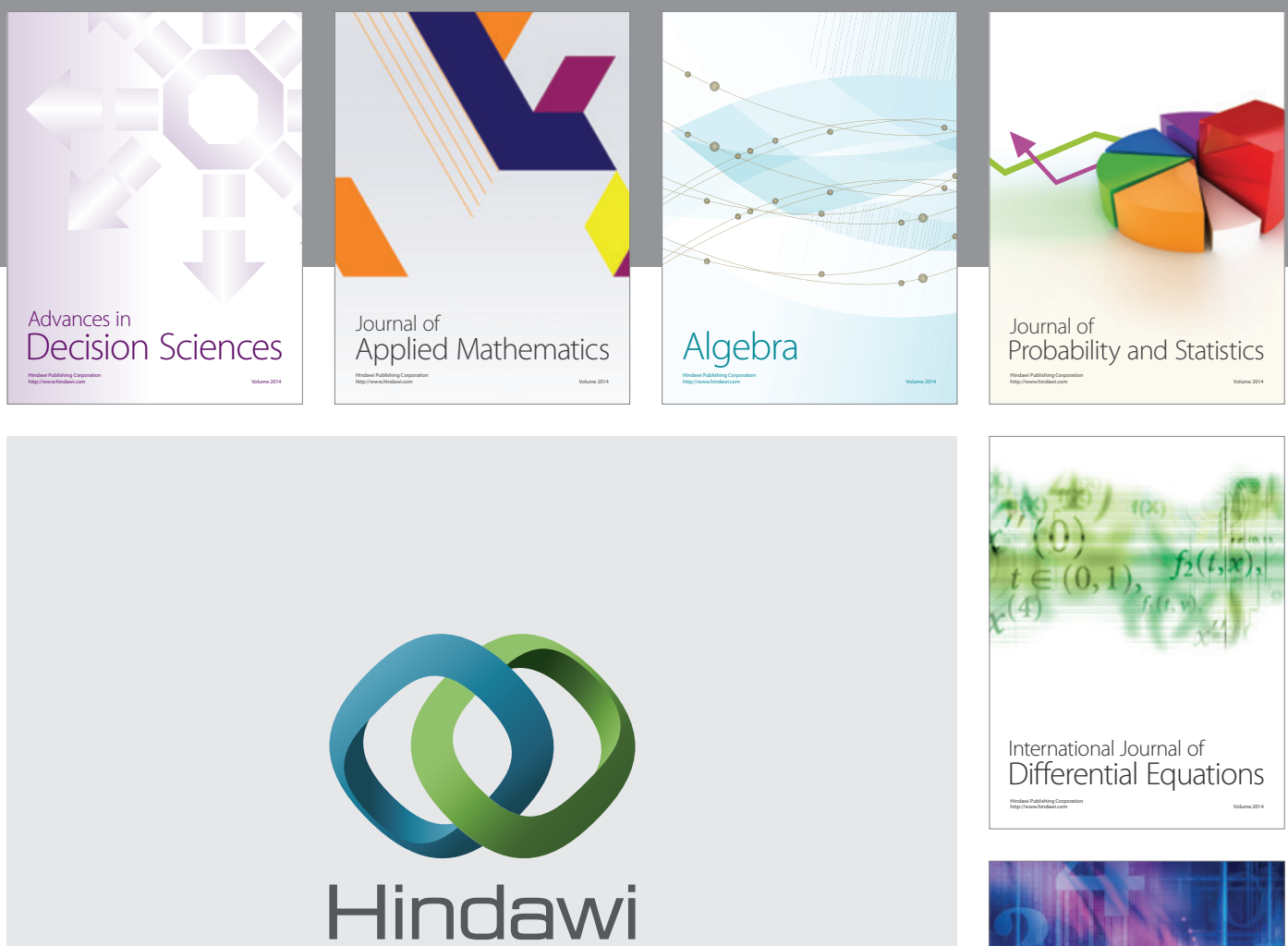

Submit your manuscripts at http://www.hindawi.com
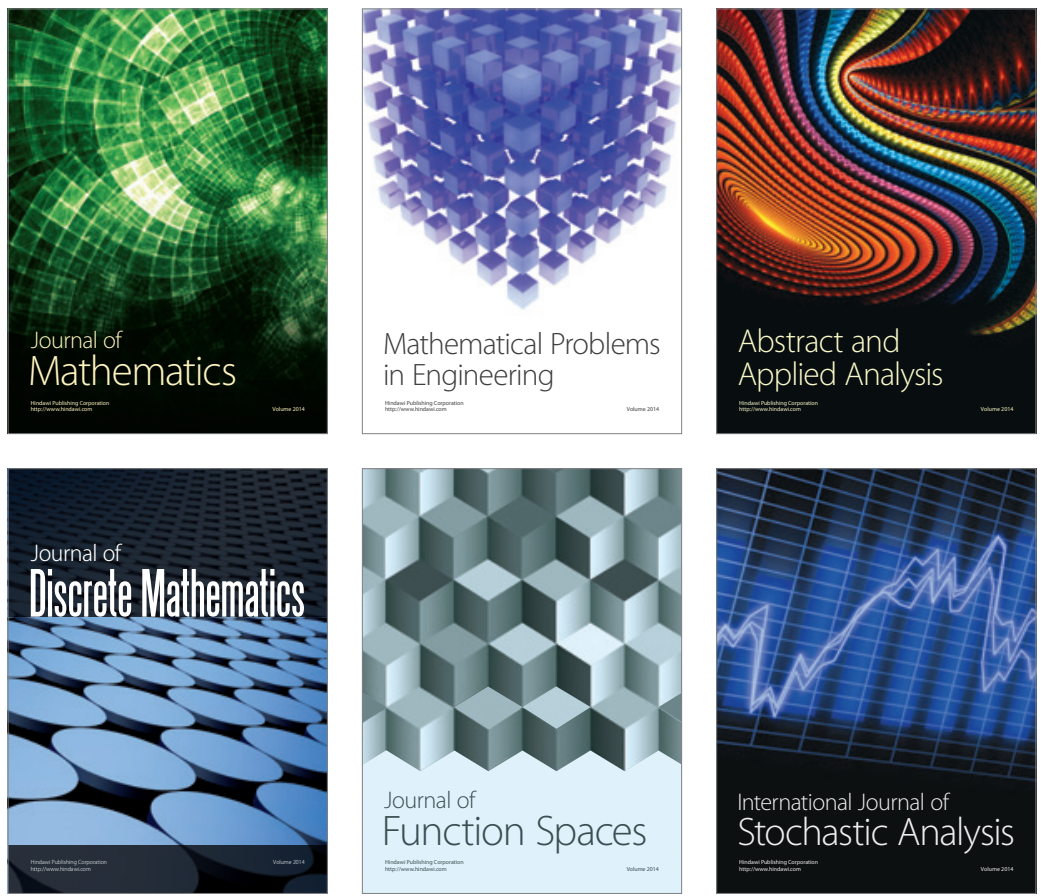

Journal of

Function Spaces

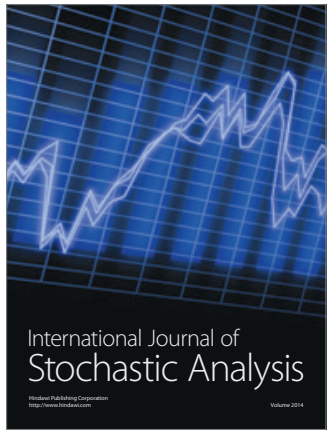

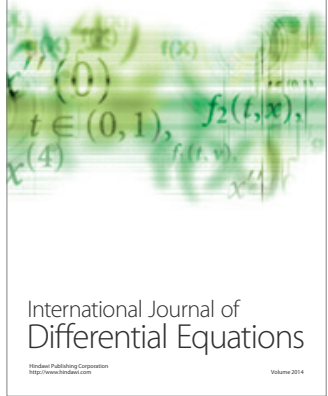
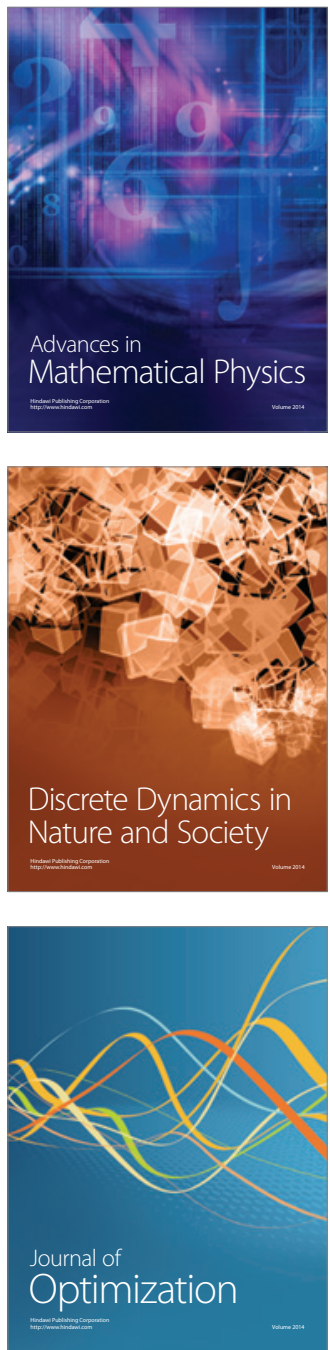